\title{
Rize İli ve İlçelerinde 50'den Az Çalışanı Olan İşyerlerinde Mevcut İş Sağlığı ve Güvenliği Uygulamaları Hakkında Bilgi Düzeyinin Belirlenmesi ve Artırılması
}

\author{
Defining and Increasing the Knowledge Levels About Current Occupational \\ Health and Safety Implementations Among Work Places with Less than
} 50 Employees in Rize Province

\author{
Tahsin Gökhan Telatar ${ }^{1}$, Mehmet Halit Baykal'2, Seçkin Karaoğlu², \\ Bilal Ataşçı², Mehmet Nuri Şafak² \\ ${ }^{1}$ Recep Tayyip Erdoğan Üniversitesi Tip Fakültesi Halk Sağlığ Anabilim Dalı, Rize \\ 2 İl Sağlık Müdürlü̆̆̈̈, Halk Sağlı̆̆ı Hizmetleri Başkanlığı, Rize \\ Yazışma Adresi / Correspondence: \\ Tahsin Gökhan Telatar \\ Recep Tayyip Erdoğan Üniversitesi Tıp Fakültesi, Dekanlık Binası. Oda No: 316. İslampaşa Mahallesi, Merkez, Rize \\ T: +905054671136 E-mail : gokhantelatar@gmail.com \\ Geliş Tarihi / Received : 11.07.2020 Kabul Tarihi / Accepted : 28.09.2020 \\ Orcid : \\ Tahsin Gökhan Telatar https://orcid.org/0000-0002-3261-3464 \\ Mehmet Halit Baykal https://orcid.org/0000-0001-9572-2513 \\ Seçkin Karaoğlu https://orcid.org/0000-0002-0114-7827 \\ Bilal Atașçı https://orcid.org/0000-0002-0751-3701 \\ Mehmet Nuri Şafak https://orcid.org/0000-0002-4220-8513 \\ ( Sakarya Tip Dergisi / Sakarya Med J 2020, 10(4):536-540) DOI: 10.31832/smj.768129
}

\footnotetext{
Öz

Amaç Araştırmanın amacı Rize ilinde Esnaf ve Sanatkârlar Odasına Kayıtlı ve 50’den az çalışanı olan işyerlerinde işyeri sahibi ya da işletmecilerin iş sağlığı ve güvenliği temel konuları hakkındaki bilgi düzeyinin saptanması, yapılandırılmış sade bir eğitim ile mevcut bilgi seviyesinin artırılması ve ilgili eğitimin etkinliğinin gösterilmesidir.

Gereç ve Bir müdahale araştırması olan bu çalışma Rize ilinde Esnaf ve Sanatkârlar Odasına Kayıtlı ve 50'den az çalşsanı olan 7103 işyerinden 5706 'sının katılımılla gerçekleștirilmiștir.

Yöntem Katılımcllara iş sağlığı ve güvenliği bilgi düzeylerini değerlendiren bir anket doldurtulmuş ve konu ile ilgili eğitim verilmiștir. On beș gün sonra katılımclların bilgi düzeyleri bir anketle tekrar değerlendirilmiștir.

Bulgular Eğitim öncesinde katılımcların iș sağlığı ve güvenliği ile ilgili bilgi düzeyleri düșük olarak tespit edilmiștir. Verilen eğitimin ardından değerlendirilen konuların tamamında yeterli bilgi sahibi olma sıklı̆̆ $\% 90$ ’n üzerine çıkmıștır. Değerlendirilen konuların tamamında eğitim öncesi ve sonrasındaki bilgi düzeylerindeki değişim istatistiksel olarak anlamlı bulunmuștur $(\mathrm{p}<0,001)$.

Sonuç İş sağlığı ve güvenliği konularında mevzuat düzenlemeleri, uygulamanın tam olması için yeterli olmamaktadır. Verilecek düzenli eğitimlerle kişilerin iş sağlığı ve güvenliği hakkındaki bilgi düzeylerinin artırılması önem taşımaktadır.

Anahtar iş sağlı̆̆ı ve güvenliği; eğitim; program etkililiği.

Kelimeler

Abstract

Objective This study aims to determine the knowledge levels about the primary subjects of occupational health and safety among the owner or manager of workplaces with less than 50 employees registered to the union of chamber of merchants and craftsmen in Rize.

Materials This cross-sectional study was conducted in 5706 workplaces out of 7103 total who are registered to the union of chamber of merchants and craftsmen in Rize with employees less than 50 . The and methods attendees' knowledge level about occupational health and safety was evaluated via a structured questionnaire, and they were trained about basic concepts of occupational health and safety. Fifteen days after the training the knowledge levels were evaluated once again.

Results The knowledge levels of the participants about occupational health and safety was low. After the training, having correct knowledge in all dimensions of the training was higher than 90\%. The increase of knowledge levels in all evaluated subjects after the training were statistically significant $(p<0.001)$.

Conclusion legislations about occupational health and safety are not enough to ensure satisfactory implementations. Increasing the knowledge levels about occupational health and safety with pieces of training has great importance.

Keywords occupational health and safety; training; program effectiveness.
} 


\section{GIIRIŞ}

İş sağlığı ve güvenliği bütün dünyada öncelikli bir halk sağlığı sorunudur. Dünyada her sene işle ilgili kazalar ve meslek hastalıklarına bağlı olarak hayatını kaybeden kişi sayısı 3,2 milyondan fazladır. Bununla birlikte dünya genelinde yılda 160 milyon yeni meslek hastalığ milyon ölümcül olmayan iş kazası meydana gelmektedir. ${ }^{1}$ Gerekli iş sağlığı ve güvenliği tedbirlerinin alınmaması ya da mevcut uygulamalardaki eksikliklere bağlı olarak meydana gelen meslek hastalıkları ile ölümlerin neden olduğu ekonomik kayıp, dünyadaki gayri safi Yurtiçi Hasılanın yaklaşık \%4'ünü oluşturmaktadır. ${ }^{2}$ Uluslararası Çalışma Örgütüne göre (ILO) dünya genelinde her yl 350 milyona yakın iş kazası ve 150 milyondan fazla meslek hastalığı ortaya çıkmaktadır. Bunların sonucunda her gün 6000 'den fazla çalışan iş kazası ya da meslek hastalıkları nedeniyle hayatlarını kaybetmektedir. ${ }^{3}$ Bu nedenle, güvenli ve sağlıklı bir iş ortamının sağlanması ve teşvik edilmesi önemli bir halk sağlığı önceliğidir. Ülkemizde iş sağlığı ve güvenliği konusunda kapsamlı mevzuat çalışmaları 2003 yılında İş Yasası ile başlamış ve 2012 yılında kabul edilip 2013 yılında yürürlüğe giren İş Sağlığı ve Güvenliği Kanunu ile hız kazanmıştır, İş Sağlığı ve Güvenliğini Geliştirme Çerçeve Sözleşmesinin (No.187, 2006) 16 Ocak 2015 tarihinde yürürlüğe girmesiyle birlikte ilgili mevzuat çalışmaları hızla ilerlemiş ve günümüzde iş sağllğı ve güvenliği uygulamaları oldukça kapsamlı bir noktaya ulaşmıştır. ${ }^{4}$

İş sağlığı ve güvenliği alanındaki uygulamalarda en önemli basamağı çalışanların uyumu ve bilgi düzeyi oluşturmaktadır. ${ }^{5}$ Mevcut düzenlemeler ne kadar yeterli olursa olsun, çalışanların uyumu tam olmadığı sürece istenen güvenli ve sağlıklı işyerlerine ulaşılması mümkün olmamaktadır. Çalışanların mevcut düzenlemelere uyumunun sağlanmasında konuya yönelik eğitimler önemli bir yer oluşturmaktadır.

Bu çalışmada Rize ilinde Esnaf ve Sanatkârlar Odasına Kayıtlı ve 50'den az çalışanı olan işyeri sahipleri veya işletmecilerinin temel iş sağlığı ve güvenliği kavramları hakkın- daki bilgi düzeylerinin saptanması, daha sonra iş sağlı̆̆ı ve güvenliği konusunda kendilerine bir eğitim verilmesi ve eğitimin sonucunda kişilerin bilgi düzeylerindeki değişimin belirlenmesi amaçlanmıştır.

\section{GEREÇ ve YÖNTEMLER}

Bu müdahale araştırması Mayıs-Haziran 2019 tarihlerinde Rize ilinde Esnaf ve Sanatkârlar Odasına kayıtlı ve 50'den az işçi çalıştıran işyerlerinin sahipleri ya da işletmecileri ile yapılmıştır. Rize ilinin Merkez dahil 11 ilçesinde bu kriterlere uyan toplam 7103 adet işyeri bulunmaktadır ve çalışma sonunda araştırmaya katılmayı kabul eden 5706 $(\% 80,33)$ işyerine ulaşılmıştır.

İşyerlerine İl Sağlık Müdürlüğü ve Toplum Sağllğ̆1 Merkezi çalışanlarınca ziyaretler yapılmış ve ilk ziyarette işyeri sahibi ya da işletmecisine iş sağllğı ve güvenliği ile ilgili temel konulardaki bilgi düzeyini ölçen kısa bir anket formu uygulanmıştır. Anket uygulamasının ardından içeriği Rize İl Sağlık Müdürlüğü tarafından geliştirilmiş olan ve iş sağlığı ve güvenliğinin temel konuları ile mevzuata bağlı zorunlulukları kapsayan bir eğitim verilmiştir. Çalışmanın bu ilk aşamasının tamamlanmasından 15 gün sonra aynı işyeri sahibi ya da işletmecilerine mevcut bilgi düzeylerini değerlendiren ikinci bir anket uygulanmış ve iki ankete verilen cevaplar değerlendirilerek hem ilk baştaki bilgi düzeyi tespit edilmiş hem de eğitim sonrasında meydana gelen bilgi düzeyindeki değişim değerlendirilmiştir.

Çalışma için Recep Tayyip Erdoğan Üniversitesi Tip Fakültesi Girişimsel Olmayan Klinik Araştırmalar Etik Kurulundan 16.04.2019 tarih ve 2019/44 sayısıla etik kurul onayı alınmış ve katılımcıların araştırmaya katılmaya gönüllü olduklarına dair imzalı bilgilendirilmiş onam formları alınmıştır.

Elde edilen veriler SPSS 18.0 programı ile analiz edilmiştir. Bilgi düzeyindeki değişimin değerlendirilmesinde $\mathrm{McNe}$ mar testi kullanılmıştır. Verilerin dağılımları sayı ve yüzde değerleri ile verilmiştir. İstatistiksel analizlerde anlamlılık 
düzeyi $\mathrm{p}<0,05$ olarak kabul edilmiştir.

\section{BULGULAR}

Çalışmada toplam 5706 işyeri ziyareti gerçekleştirilmiştir. İlçelere göre ziyaret edilen işyeri sayıları Tablo 1'de sunulmuştur. \begin{tabular}{l}
$\begin{array}{l}\text { Tablo 1. Rize ilinde ziyaret edilen işyerlerinin ilçelere göre } \\
\text { dağıımı. }\end{array}$ \\
\hline
\end{tabular}

\begin{tabular}{|l|c|c|}
\hline & Sayı & Yüzde \\
\hline İkizdere & 80 & 1,40 \\
\hline Derepazarı & 172 & 3,01 \\
\hline Hemşin & 122 & 2,14 \\
\hline Pazar & 934 & 16,37 \\
\hline Fındıklı & 1274 & 22,33 \\
\hline Çamlıhemşin & 78 & 1,37 \\
\hline Merkez & 328 & 5,75 \\
\hline Kalkandere & 156 & 2,73 \\
\hline İyidere & 218 & 3,82 \\
\hline Ardeşen & 1280 & 22,43 \\
\hline Çayeli & 788 & 13,81 \\
\hline Güneysu & 276 & 4,84 \\
\hline Toplam & 5706 & 100,00 \\
\hline
\end{tabular}

Verilen eğitim öncesinde bilgi düzeyinin en düşük olduğu konu, işverenlerin iş sağlı̆̆ı ve güvenliği ile ilgili hizmetleri nereden alacaklarını bilme durumları olarak saptanmıştır. Katılımcıların sadece \%61,16'si ilgili hizmetleri nereden alacaklarını bildiklerini belirtmişlerdir. Bilgi seviyesinin en yüksek olduğu konu ise \%83,98 ile İş Sağlığ 1 ve Güvenliği Kanununun varlığını bilme olarak tespit edilmiştir. Verilen eğitimin sonunda yapılan değerlendirmede eğitim verilen tüm alanlarda bilgi düzeyi \%90’ın üzerine çıkmıştır. En yüksek artış \%35,41 ile iş sağlı̆̆ı ve güvenliği ile ilgili hizmetleri nereden alacaklarını bilme durumlarında gözlenmiştir (Tablo 2).

Katılımcıların eğitim öncesi ve sonrası iş sağlığı ve güvenliğinin temel konularına ilişkin bilgi düzeylerindeki değişimler her alanda artış göstermiş ve tüm alanlardaki artışlar istatistiksel olarak anlamlı bulunmuştur $(\mathrm{p}<0,001)$ (Tablo 3).

\begin{tabular}{|c|c|c|c|c|c|}
\hline & & Ĕ̆g & cesi & Eği & nrasi \\
\hline \multirow{2}{*}{ İş Sağlığı ve Güvenliği Kanununu bilme durumu } & Evet & 4792 & 83,98 & 5642 & 98,88 \\
\hline & Hayır & 914 & 16,02 & 64 & 1,12 \\
\hline \multirow{2}{*}{ İş sağlığı ve güveliği uygulamalarının amacını bilme durumu } & Evet & 4406 & 77,22 & 5594 & 98,04 \\
\hline & Hayır & 1300 & 22,78 & 112 & 1,96 \\
\hline \multirow{2}{*}{ Kanuna göre işyerlerinin tehlike sınıflarını bilme durumu } & Evet & 3734 & 65,44 & 5368 & 94,08 \\
\hline & Hayır & 1972 & 34,56 & 338 & 5,92 \\
\hline \multirow{2}{*}{ İş kazası kavramı ve tanımını bilme durumu } & Evet & 4786 & 83,94 & 5630 & 98,67 \\
\hline & Hayır & 916 & 16,06 & 76 & 1,33 \\
\hline \multirow{2}{*}{$\begin{array}{l}\text { İş sağlığı ve güvenliğine ilişkin hizmetleri nereden alabileceğini bilme } \\
\text { durumu }\end{array}$} & Evet & 3490 & 61,16 & 5510 & 96,57 \\
\hline & Hayır & 2216 & 38,84 & 196 & 3,43 \\
\hline
\end{tabular}


Sakarya Tip Dergisi 2020;10(4):536-540

TELATAR ve Ark., İș Sağlığı ve Güvenliği Bilgi Düzeyine Eğitimin Etkisi

Tablo 3. Katılımcıların verilen eğitim öncesi ve sonrasında iş sağlığı ve güvenliğine ilişkin temel konulardaki bilgi düzeylerinin karşılaştırılması.

\begin{tabular}{|c|c|c|c|c|c|c|}
\hline & & Ĕgiti & ncesi & Eğiti & nrası & $\mathbf{p}$ \\
\hline \multirow{2}{*}{ İş Sağlığı ve Güvenliği Kanununu bilme durumu } & Evet & 4792 & 45,93 & 5642 & 54,07 & \multirow{2}{*}{$<0,001$} \\
\hline & Hayır & 914 & 93,46 & 64 & 6,54 & \\
\hline \multirow{2}{*}{ İş sağlığı ve güveliği uygulamalarının amacını bilme durumu } & Evet & 4406 & 44,06 & 5594 & 55,94 & \multirow{2}{*}{$<0,001$} \\
\hline & Hayır & 1300 & 92,07 & 112 & 7,93 & \\
\hline \multirow{2}{*}{ Kanuna göre işyerlerinin tehlike sınıflarını bilme durumu } & Evet & 3734 & 41,02 & 5368 & 58,98 & \multirow{2}{*}{$<0,001$} \\
\hline & Hayır & 1972 & 85,37 & 338 & 14,63 & \\
\hline \multirow{2}{*}{ İş kazası kavramı ve tanımını bilme durumu } & Evet & 4786 & 45,95 & 5630 & 54,05 & \multirow{2}{*}{$<0,001$} \\
\hline & Hayır & 916 & 92,34 & 76 & 7,66 & \\
\hline \multirow{2}{*}{$\begin{array}{l}\text { İş sağlığı ve güvenliğine ilişkin hizmetleri nereden alabileceğini bilme } \\
\text { durumu }\end{array}$} & Evet & 3490 & 38,78 & 5510 & 61,22 & \multirow{2}{*}{$<0,001$} \\
\hline & Hayır & 2216 & 91,87 & 196 & 8,13 & \\
\hline
\end{tabular}

\section{TARTIŞMA}

Mevcut literatüre göre ülkemizde İş Sağlı̆̆ı ve Güvenliği ile ilgili mevzuatın uzun bir geçmişi olmasına rağmen konu ile ilgili bilgi düzeyi yeterli seviyede değildir. Burunkaya ve arkadaşlarının 2017 yılında 521 sağlık çalışanı arasında yaptığı araştırma sonucunda iş sağlığı ve güvenliği konusundaki bilgi düzeyi düşük olarak tespit edilmiştir. ${ }^{6}$ Gıda üretiminde faaliyet gösteren esnafların iş sağlığı ve güvenliği algısı üzerine yapılan bir araştırma algı düzeyinin orta seviyede olduğunu tespit etmiştir. ${ }^{5}$ İş sağlığ 1 ve güvenliği ile ilgili bilgi düzeyinin düşük olması, gerekli uygulamalara uyumun da yeterli seviyede olmamasina neden olmaktadır. ${ }^{7}$ Benzer şekilde iş sağlığı ve güvenliğine ilişkin eğitimler, bireylerin kurallara uyumunu artırmaktadır. İnanç ve arkadaşlarının 2019 yılında orman fidanlıklarında çalışanlarla yaptıkları bir çalışmada düzenli olarak iş sağlığı ve güvenliği konularında eğitim verilmesinin, uygulamalara uyumu artırdığı gösterilmiştir. $^{8}$

Bu çalışmayla hedefe yönelik olarak yapılandırılmış sade bir eğitim programıyla, işverenlerin iş sağlığı ve güvenliği konusundaki bilgi düzeyleri istatistiksel olarak anlamlı düzeyde artırıldığı gösterilmiştir. İş sağlığı ve güvenliği konusunda etkili mevzuatlara sahip olmak büyük önem taşımakla birlikte, bu mevzuatlara uyumun istenilen seviyelerde olması için düzenli olarak hedef gruplara yönelik eğitimler düzenlenmesi fayda sağlamaktadır.

\section{Çıkar ilişkisi}

Herhangi bir çıkar ilişkisi bulunmamaktadır.

Etik kurul onayının alındığı kurum

Recep Tayyip Erdoğan Üniversitesi Tıp Fakültesi, Girişimsel Olmayan Klinik Araştırmalar Etik Kurulu

Tarih: 16.04.2019

Karar numarası: 2019/44 
Sakarya Tip Dergisi 2020;10(4):536-540

TELATAR ve Ark., İş Sağlığı ve Güvenliği Bilgi Düzeyine Eğitimin Etkisi

\section{Kaynaklar}

1. Bilir N. İşSăglı̆̆ı ve Güvenliği: Güneș Tip Kitabevi; 2016.

2. SGK Istatistik ylliklari. 2018. Accessed at 19.03.2019, at http://www.sgk.gov.tr/wps/portal/ sgk/tr/kurumsal/istatistik/sgk_istatistik_yilliklari.)

3. World Statistic. 2019. (Accessed 19.03.2019, at https://www.ilo.org/moscow/areas-of-work/ occupational-safety-and-health/WCMS_249278/lang--en/index.htm.)

4. Bilir N, Yıldız A. İș sağlğı ve güvenliği mevzuatı. In: Bilir N, Yıldız AN, eds. İş Săğlğı ve Güvenliği. Ankara: Hacettepe Üniversitesi Yayınlarl; 2013:638-74.

5. Cerev G. Gıda üretiminde faaliyet gösteen esnaflarda iş sağlı̆̆ı ve güvenliği algıst üzerine nitel bir arașttrma. Atlas Journal 2020;6:137-46.
6. Burunkaya B, Topal K, ERDOĞDU UDG, GEREKLIOĞLU UDÇ. Sağlik Çalışanlarının Çalıșan Güvenliği Uygulamalarından Memnuniyetleri ve İș Sağllğı ve Güvenliği Kanunu Hakkındaki Bilgi Düzeyleri. Sağlıkta Performans ve Kalite Dergisi;13:1-17.

7. Aktuna A. Tarım sektöründe çalışanların iş sağlğ̆ı ve güvenliğgi çerçevesinde bilgi, tutum ve algı düzeyleri: Tekirdă̆ Süleymanpaşa örneği. Yüksek Lisans Tezi, Tekirdağ: Namık Kemal Üniversitesi Sosyal Bilimler Enstitüsü; 2017.

8. İnanç $S$, Cevdet A. Orman fidanlıklarında çalıșma koşulları ve iş güvenliği uygulamaları (Erzurum Orman Fidanlik Müdürlüğü örneği). Journal of Anatolian Environmental and Animal Sciences 2019;4:64-9. 